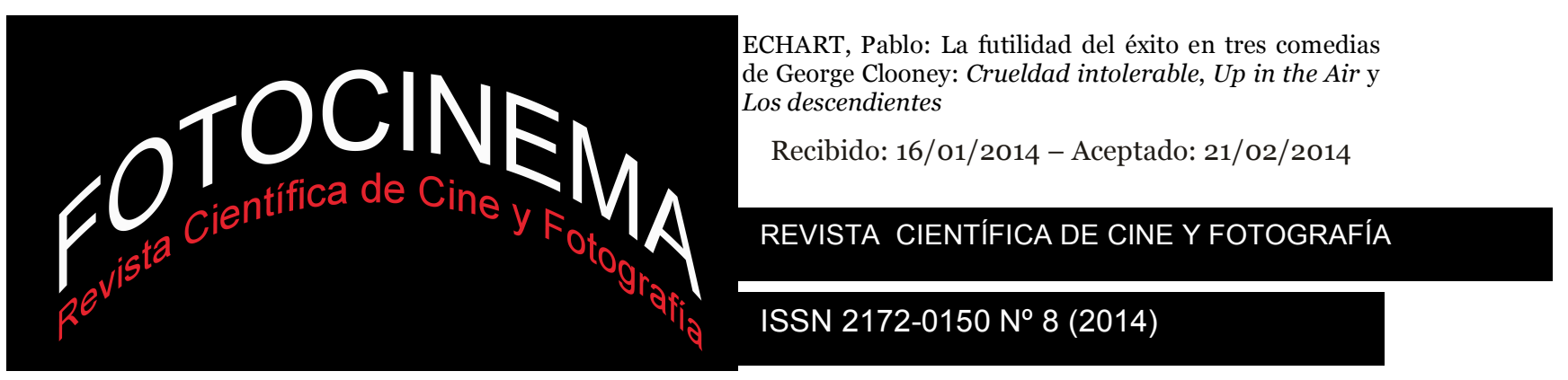

\title{
LA FUTILIDAD DEL ÉXITO EN TRES COMEDIAS DE GEORGE CLOONEY: CRUELDAD INTOLERABLE, UP IN THE AIR Y LOS DESCENDIENTES
}

\section{THE FUTILITY OF SUCCESS IN THREE COMEDIES OF GEORGE CLOONEY: INTOLERABLE CRUELTY, UP IN THE AIR, THE DESCENDANTS}

\section{Resumen:}

Los roles dramáticos desempeñados por George Clooney en Crueldad intolerable, Up in the Air y Los descendientes muestran una notable afinidad en tanto que expresan la vacuidad de unas biografías perfiladas bajo el prisma del éxito individual. Los personajes de Miles Massey, Ryan Bingham y Matt King son presentados en estos relatos como triunfadores narcisistas o ensimismados que, sin embargo, caen en la cuenta de la futilidad de su cosmovisión, edificada sobre valores como la eficiencia profesional, el prestigio personal y el lujo. Estos hombres de mediana edad reciben la oportunidad de rehacer sus vidas, encontrando éstas sentido en el establecimiento de genuinos vínculos afectivos de carácter romántico, familiar e, incluso, con el espacio que habitan. Este artículo pretende analizar la subjetividad de estos protagonistas, mostrar las estrategias dramáticas que los mueven al cambio y posibilitan su arco de crecimiento, y constatar en qué valores se cifra la redención de su identidad. Con la exageración que es propia a la comedia, la evolución interna de estos personajes ilustrará, en definitiva, las limitaciones de un mito -el del éxito- profundamente arraigado en la cultura estadounidense.

Palabras clave:

Éxito; George Clooney; Crueldad intolerable; Up in the Air; Los descendientes; narcisismo Keywords:

Success; George Clooney; Intolerable Cruelty; Up in the Air; The Descendants; narcissism

Texto resultado del proyecto de investigación I+D "Imaginarios de la crisis: Las representaciones audiovisuales de la quiebra económica, social y geopolítica (1929-2012)", financiado en 2013 por el Ministerio de Economía y Competitividad, referencia CSO2012-33782.

\begin{abstract}
:
The dramatic roles played by George Clooney in Intolerable Cruelty, $U p$ in the Air, and The descendants show a remarkable affinity in the way they express the emptiness of life stories constructed under the perspective of individual success. The characters of Miles Massey, Ryan Bingham and Matt King are presented in these stories as narcissistic or self-centered winners who end up, however, realizing the futility of their worldview, built on values such as professional efficiency, personal prestige and luxury. These middle-aged men have the chance to rebuild their lives, finding meaning in establishing genuine affective bonds of romantic and familial nature, and even with the space they inhabit. This article aims to analyze the subjectivity of these characters, the dramatic strategies that propel their change and enable their arch of growth, and the key-values in their redemption. With the exaggeration inherent to comedy, the internal evolution of these characters illustrates, ultimately, the shortcomings of the myth of success, so deeply rooted in American culture.
\end{abstract}




\section{Introducción}

Acorde con un tiempo en el que "las estrellas se moldean a sí mismas, y a sus marcas, a través de sus propios actos públicos” (Traub, 2008, p. 1), ciertas celebrities de Hollywood se han convertido en actores activos de cuestiones políticas y sociales. George Clooney, el actor más emblemático del cine estadounidense de la actualidad, puede encarnar el mejor ejemplo de esta tendencia. Desde comienzos del siglo XXI, Clooney ha mostrado públicamente una clara significación ideológica y un compromiso con relevantes causas sociales y políticas de ámbito nacional e internacional, con las que se ha situado en las primeras filas del progresismo de Hollywood (Sterritt, 2012, pp. 220 y 221). Su amistad con el Presidente Obama es un fiel indicador en este sentido.

Parejo a este interés por asuntos de la esfera pública, cabe constatar que un significativo número de los proyectos cinematográficos en los que participa habitualmente como actor, si bien también en ocasiones como productor y director - tiene pretensiones de trascender el puro entretenimiento. De acuerdo con Sterritt (p. 223), su trabajo fílmico entre 2000 y 2010 indica que Clooney está dispuesto y desea invertir un gran capital en proyectos fílmicos de evidente contenido sociopolítico.

Vinculado al Sueño Americano, el mito del éxito tiene en la cultura estadounidense una preminencia sobresaliente y, como no podía ser de otra manera, la ficción cinematográfica ha desempeñado un rol primordial en su reflejo e impulso (Levinson, 2012, p. 1). En su filmografía, George Clooney no es ajeno a este fenómeno. A primera vista, resulta de interés percibir cómo su imagen cinematográfica se viene cincelando en buena medida sobre personajes que, aun reflejando posturas morales muy distintas, coinciden en ser una suerte de "profesionales aristocráticos", si se entiende por ello la alta cualificación y el reconocimiento que gozan en sus ámbitos de trabajo.

Este sería el caso de los tres filmes que aquí se van a analizar -Crueldad intolerable (J. Coen, 2003), Up in the Air (J. Reitman, 2009) y Los descendientes (A. Payne, 2012)-, y de otros como Los idus de marzo (G. Clooney, 2011), El americano (A. Corbijn, 2011), Michael Clayton (T. Gilroy, 2007), Syriana (S. Gaghan, 2005), Buenas noches, y buena suerte (G. Clooney, 
2005), o Gravity (A. Cuarón, 2013)1. Desde la reverencia o desde la burla, se percibe un interés en las interpretaciones recientes de Clooney por el deber ser de las profesiones, así como por las implicaciones que en la vida de los ciudadanos comunes tiene el comportamiento de los personajes que pertenecen a una elite profesional.

En este estudio se han elegido una comedia romántica (Crueldad intolerable) y dos comedias dramáticas (Up in the Air y Los descendientes) que reflejan una temática común: el desarraigo de unos profesionales de éxito a los que se les brinda la oportunidad de experimentar una suerte de resurrección a la vida, la cual consistirá grosso modo en la germinación de unas relaciones sentimentales y familiares genuinas, con las que podrán poner fin a su ensimismamiento. Miles Massey (Crueldad intolerable) y Ryan Bingham (Up in the Air) son dos narcisistas radicales, representantes de un individualismo feroz en su modo de entender el trabajo y las relaciones personales; mientras que Matt King (Los descendientes) es un hombre que, sin caer en el narcisismo, representa a una mentalidad de antaño en la que el varón centraba su atención en la esfera del trabajo, y era la mujer la que se ocupaba de atender el hogar y los aspectos afectivos de sus componentes.

\section{Marco teórico y metodología}

Este artículo entronca, en primera instancia, con el fenómeno del estrellato cinematográfico. Richard Dyer establece en su canónico estudio que la imagen de una estrella depende tanto de elementos paratextuales como textuales (2001, pp. 85-88). Entre los primeros, Dyer alude a la promoción, a los comentarios y a las críticas; también a la publicidad, entendida como la creación de una imagen de apariencia no deliberada que se presenta como más auténtica en tanto que "se supone que ofrece un acceso privilegiado a la personalidad real de la estrella" (p. 86). Los medios de comunicación se hacen ecos de esta publicidad y muestran las tensiones existentes entre la imagen de la estrella como persona y

\footnotetext{
${ }^{1}$ En esta última, la obsesión de Matt Kowalski - su personaje- por perpetuarse en la Historia como el astronauta que más tiempo ha pasado fuera de la cápsula espacial - con el resultado que bien conocemos- puede interpretarse como una amable autoparodia de esta imagen cinematográfica de George Clooney sustentada sobre exitosos profesionales. No es el único caso en el que Clooney ha sabido reírse de ello: mucho más incisivas son en este sentido las películas de los hermanos Coen O Brother! (2000) y Quemar después de leer (2008).
} 
la imagen que proyecta a través de sus roles cinematográficos, si bien es también posible explorar las posibles convergencias entre una y otra, como aquí se va a hacer.

De alguna manera, el interés demostrado por Clooney hacia asuntos de interés público en su faceta como ciudadano encuentra un trasunto en su trayectoria cinematográfica, con la que evidentemente afianza las connotaciones específicas de su identidad como estrella: "Como estrellas anteriores de Hollywood tan diferentes como Charles Chaplin y Katharine Hepburn, o Joan Crawford y John Wayne, Clooney ha puesto su trabajo más inspirado al servicio de la creación de sí mismo" (Sterritt, p. 235). Mencionados los vasos comunicantes entre la imagen pública y la imagen cinematográfica, lo relevante a efectos de esta investigación se emplaza efectivamente en los roles dramáticos encarnados por Clooney en las tres películas escogidas, por el rico valor simbólico y cultural que, en su condición de estrella (McDonald, 2013, p. 1), resulta de ellos.

De manera específica, en este artículo se ha tomado como punto de referencia un mito estadounidense por excelencia, el del éxito, colofón inexcusable del American Dream. Como no puede ser de otra manera, el cine se ha hecho eco de este mito en múltiples ocasiones, y la literatura académica al respecto es considerable. En este trabajo se ha encontrado una útil referencia en The American Success Myth on Film, la reciente monografía compilatoria de Julie Levinson sobre las principales expresiones (positivas y negativas) del mito en el cine. Más en concreto, este artículo se articula en torno a tres películas protagonizadas por George Clooney que ilustran una patología derivada del mito del éxito y que encuentra acomodo en una concepción extremadamente individualista del ser humano. Crueldad intolerable, Up in the Air y Los descendientes, con la exageración que permite la comedia, ilustran en efecto el narcisismo (en el caso de las dos primeras) y el solipsismo (en el caso de las tres) de unos protagonistas masculinos que, a la postre, encontrarán en la apertura hacia la alteridad una vía de significado para sus vidas de apariencia plena pero de sentido estéril.

Este malestar individual pero imbricado en un ethos cultural está profusamente documentado en el ámbito de las Ciencias Sociales, y en la medida en que el cine sirve de espejo de la comunidad en la que se gesta, los estudios fílmicos también 
han analizado las formas en las que el cine ha dado cuenta del mismo. Dentro de nuestras fronteras, el reciente trabajo de Orellana (2010) procura recoger cuáles son las manifestaciones del narcisismo en el cine contemporáneo y las posibles vías que éste mismo plantea para superarlo. Haciéndose eco de referencias ya clásicas como las de Lasch (La cultura del narcisismo), Lipovetsky (La era del vacío) o Taylor (La ética de la autenticidad), el autor repasa las principales cualidades asociadas al sujeto narcisista (pp. 39-43), y es fácil reconocer en los protagonistas elegidos en esta muestra algunos de sus rasgos dominantes, como pueden ser el privilegio rotundo de la propia subjetividad, la pérdida del sentido de la culpa, la satisfacción respecto a la propia imagen o, también, la aparición de episodios melancólicos que denotan su vacío o insatisfacción.

Esta investigación se realiza a partir de la metodología clásica del análisis textual y, como se advierte, pone el foco en la construcción dramática de los personajes protagonistas de las tres películas señaladas. El artículo analiza su subjetividad y atiende a los elementos narrativos que favorecen su arco de crecimiento vital. Aun prescindiendo de rígidas clasificaciones, el análisis de estos caracteres abundará en aspectos vinculados a la tridimensionalidad de personajes propugnada por Egri (1960, pp. 32-43), es decir, en alusiones referidas a sus condiciones fisionómicas, sociológicas y psicológicas; se indicarán conflictos dominantes y convenciones dramáticas que acaecen en los relatos; e incluso se realizarán referencias a cineastas y precedentes cinematográficos que ayudan a contextualizar los viajes interiores de estos personajes.

En definitiva, a través de una parcial pero unitaria aproximación a la filmografía de un actor de relevante impacto social, se pretende examinar cómo se refleja en la ficción cinematográfica una patología derivada de un mito superlativo -el del éxito- de la sociedad norteamericana.

\section{Miles Massey: el triunfador de los divorcios}

Crueldad intolerable supone un homenaje y una evidente puesta al día de los códigos narrativos y temáticos de la comedia romántica del Hollywood de los años treinta y cuarenta, la cual aporta un capítulo distintivo a la estrecha relación del cine estadounidense con el fecundo mito cultural del éxito 
profesional. En aquella expresión del género, la esfera laboral -en la que abundaban excelentes representantes de profesionales liberales: investigadores, periodistas, abogados...- podía convertirse en un espacio de realización personal, en la medida en que los protagonistas lo convertían junto a sus parejas en un terreno lúdico y excitante, y prescindían de priorizar los logros económicos que de su actividad pudieran devenirse. Junto a esta lectura eminentemente positiva de la profesión como ámbito de realización, también abundaban en la screwball comedy las advertencias sobre las patologías resultantes de una dedicación desmedida u obsesiva al trabajo - es más, con frecuencia se ensalzaba el ocio-, lo cual podía privar de los verdaderos goces de la vida, y las invitaciones a la alta sociedad a liberarse de las esclavitudes derivadas de las riquezas materiales. Así, mediante distintas estrategias narrativas, la comedia de los sexos incidía en la necesidad de renunciar al dinero como valor supremo y, en cambio, apostaba la vida lograda al encuentro amoroso con un ser que a un tiempo aunaba la oposición y la complementariedad y con el que se hacía posible exprimir, en presente, las posibilidades de cada día (Echart, 2005, pp. 262-263).

Ambientada en un Los Ángeles actual, Crueldad intolerable recoge el testigo de esa corriente de la screwball comedy que reprende a la clase adinerada, cuyo credo - y ceguera cómica- consiste en esta ocasión en "posesiones materiales, cuentas bancarias, y dentaduras perfectas" (Doom, 2009, p. 128). A través de sus protagonistas Miles Massey (George Clooney) y Marilyn (Catherine Z. Jones), la película se vertebra sobre el esquema antagónico entre el amor y el culto al dinero, el cual impide las relaciones personales genuinas. Moldeada sobre el patrón de las "cazafortunas" de la screwball comedy y en el que destacó el atrevimiento de las creaciones femeninas de Preston Sturges -la Eve de Medianoche (M. Leisen, 1939), la Jean/Eve de Las tres noches de Eva (P. Sturges, 1941), la Gerry de Un marido rico (P. Sturges, 1942)-, Marilyn las iguala en astucia y en la seguridad que posee respecto al poder de su atractivo físico como arma de seducción, y las rebasa en amoralidad para erigirse posiblemente en el personaje femenino más cínico que jamás haya comandado una comedia romántica. Marilyn ha hecho del matrimonio - es decir, del divorcio- su profesión: la fuente de ingresos con la que aspira a financiarse "la riqueza, la independencia y la libertad". El matrimonio es para ella un negocio 
que le ha reportado una fortuna obscena y que gobierna con lógica empresarial, como se advierte en su intención de buscar maridos divorciados varias veces (la inestabilidad es un valor: con mayor rapidez y menos tiempo conseguirá su dinero) o, ante una "oferta" matrimonial que le brinda una de sus amigas, apuesta por no precipitarse e ir "de uno en uno". Como ilustran expresiones en las que los hombres son presentados como alimento - "yo me meriendo a los hombres como usted", le dice a Miles- o reducidos a condición animal, Marilyn es una depredadora. En definitiva, su visión del matrimonio es radicalmente cínica y utilitarista, y está despojada por completo de cualquier vínculo afectivo y de la voluntad de compromiso que se le presume a esta institución.

Miles, por su parte, es un abogado especializado en divorcios, alguien que se gana la vida con las desgracias ajenas (Sickels, 2008, p. 121). En esta profesión ha obtenido tanto éxito como Marilyn en la suya, y a ella se entrega con una amoralidad y un cinismo igualmente ilimitados. Como atestigua la primera imagen que de él se obtiene [fig. 1], un primer plano de su dentadura (por la cual siente obsesión), su condición también es la de un depredador (Rowell, 2007, p. 325) $)^{2}$. La elegancia y la opulencia de los espacios que ambos transitan, extensivos al cortejo de abogados que los secundan, no dan fe de un universo civilizado sino de su contrario: una jungla donde impera la supervivencia del más fuerte a costa de los otros, y donde el entendimiento, el acuerdo y la justicia son conceptos inexistentes.

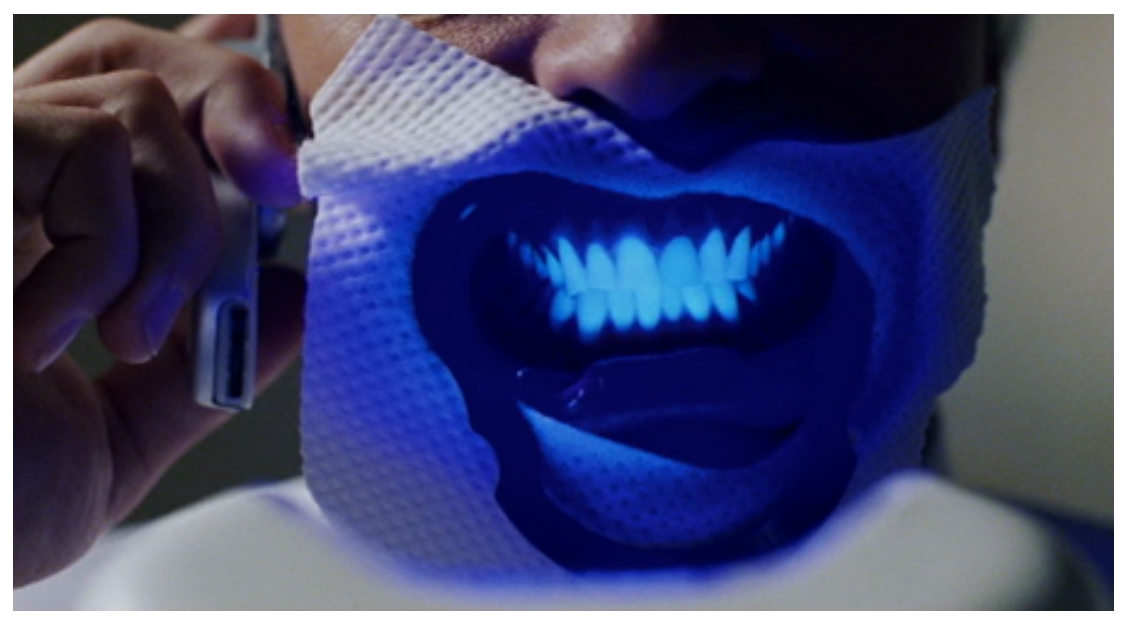

\footnotetext{
${ }^{2} \mathrm{Su}$ dentadura, en efecto, es un signo de poder, pero también le sirve a Miles para mostrar una proverbial sonrisa con la que "realza su propia apariencia y la apariencia de sus argumentos en su camino hacia la victoria" (Conard, 2008, p. 113).
} 
El retrato psicológico de Miles es dibujado en las primeras secuencias en las que interviene. En ellas se advierte que si es un triunfador en este despiadado hábitat profesional, se debe a que enarbola con ardor los valores salvajes que rigen en él, y que no dejan resquicio para el más elemental comportamiento moral. La primera de las dos secuencias acontece en su despacho, donde una mujer demanda sus servicios para que Miles la proteja de su marido, quien la sorprendió en una flagrante infidelidad. El "saber hacer" de Miles se advierte en primer lugar en su capacidad para improvisar una versión completamente distorsionada $-\mathrm{y}$ favorable, por descontado, a los intereses de su clienta- de los hechos, con lo que demuestra un desprecio absoluto por la verdad acaecida y la falta de escrúpulos para vencer al contrario a cualquier precio; al mismo tiempo, adopta una jerga bélica para exponer la estrategia que seguirá en el caso; también acepta el caso porque "es un desafío", es decir, un litigio lo suficientemente complicado como para sacarle de la rutina (aspecto que, como se verá enseguida, tiene su importancia); y reconoce para sí como mérito profesional un recurso innoble del que dispone la parte contraria: como él mismo hace, valora la capacidad del oponente para tratar de imponerse, haciendo legítimo para ello cualquier medio. La presentación del personaje es completada a renglón seguido con su actuación en un juicio de divorcio de dos ancianos, en el que demuestra su pericia retórica (y, huelga decirlo, sus malas artes). Ante Wrigley, su segundo de a bordo y confidente, Miles expresa su visión del matrimonio como epítome de lo que él entiende es la muerte, es decir, el acuerdo y la negociación. Lo suyo, añade, es la aniquilación del contrario, principio que aplica de manera consecuente y a rajatabla como abogado: entre sus víctimas se encuentra una mujer rica que pasó a ser una vendedora de McDonalds o un exitoso productor televisivo reducido a la condición de mendigo [fig. 2].

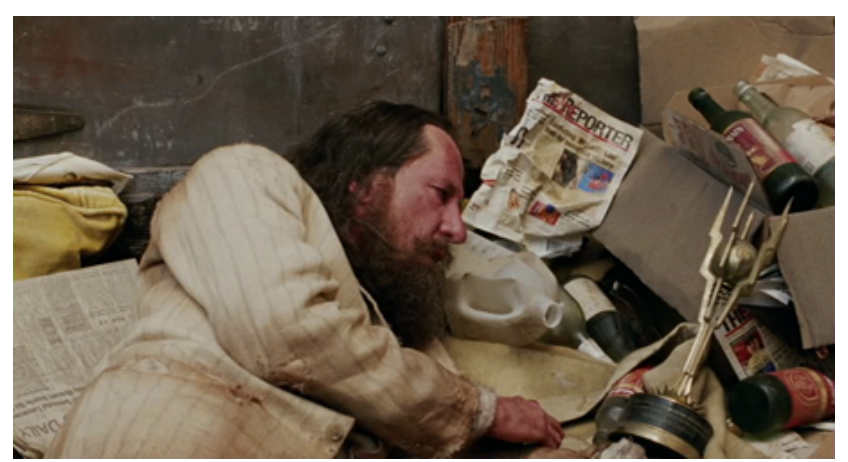


Miles representa la viva imagen del éxito: dispone de una ingente cantidad de dinero y puede poseer las posesiones materiales que desee, atesora una espectacular carrera de victorias en los tribunales, cuenta con el reconocimiento del fundador de su bufete, $\mathrm{y}$ ha hecho realidad su sueño de logros a través de la destrucción (Conard, 2008, p. 120). Sin embargo, el éxito no se traduce en un estado de felicidad plena y tiene, por tanto, sus limitaciones. En la misma secuencia, este triunfador reconoce ante su ayudante sentirse insatisfecho. Se infiere que Miles vive recluso en una cárcel de cristal, ajeno a las gratificaciones propias de un estilo de vida convencional, del que sin embargo huye (Doom, 2009, p. 128). Como tantos personajes acomodados de la screwball comedy, se siente aburrido y no ve en la explotación de su riqueza material un remedio a esta crisis personal. Aunque estas consideraciones melancólicas son barridas por su obsesión por el triunfo profesional, con este reconocimiento se abre para él la posibilidad de un necesario cambio de valores3.

Otro vector que trabaja en la misma dirección es el influjo -inclusive a través de pesadillas- que ejerce sobre él la grotesca y ominosa figura de Herb, el socio fundador del bufete para el que trabaja. Miles está llamado a suceder a este personaje que vive para el trabajo y que aparece revestido de fuertes connotaciones demoniacas (Rowell, 2007, p. 310): carece de intestinos (es decir, de entrañas), habita un despacho en un sótano instalado en la penumbra, y goza del mismo cinismo que Miles respecto a la profesión y de su escepticismo respecto al matrimonio, por lo que bien pudiera haber ejercido sobre él una acción mentora. Su dificultad para respirar y los abundantes monitores conectados a su cuerpo hacen sospechar la inmediatez de su muerte y, con ella, la sucesión de Miles como cabeza de la firma y la certeza de que, más tarde o más temprano, éste repetirá la misma suerte de aquel: la proyección del éxito profesional en el futuro equivale al infierno en vida [fig. 3 y 4 ].
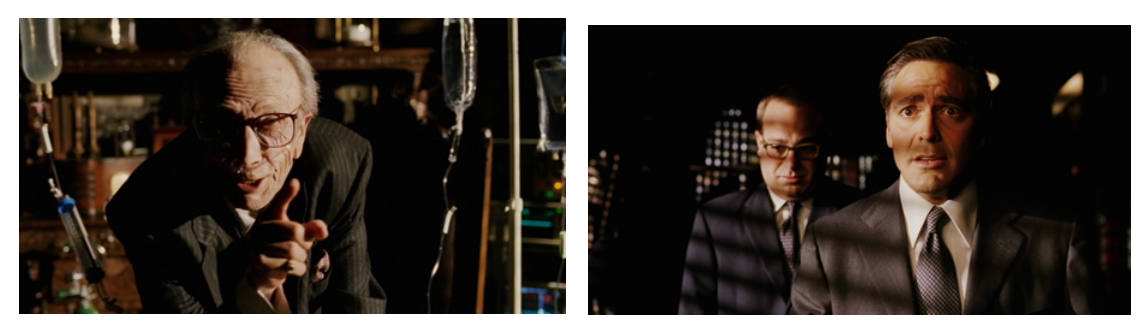

\footnotetext{
3 El relato plantea también una fisura paralela en el personaje de Marilyn, al hacerle capaz de apreciar, a través de los desvelos de una amiga suya, las exigencias y las limitaciones vitales de una vida consagrada a amasar una fortuna.
} 
Además de estos apoyos y según corresponde a las convenciones de la comedia romántica, es en la esfera de la guerra de los sexos donde tienen lugar las principales mutaciones de Miles (y las de Marilyn), la modificación de sus prioridades vitales. La batalla se origina en el momento en el que Miles decide defender en los tribunales $-\mathrm{y}$ lo hace con éxito- al último marido de Marilyn, con lo que impide en primera instancia que ella se haga con su fortuna. A partir de aquí ella lleva a cabo un abigarrado plan de revancha con el que aspira arrebatarle a Miles la mitad de su capital. Para ello le confunde con diversas argucias, haciéndole creer que ella ha modificado su percepción sobre el matrimonio, al que parece entregarse de manera genuina, sin considerarlo como una operación económica.

Aunque afectan a su bolsillo, las charadas de Marilyn -que incluyen una boda falsa de ella con un supuesto rústico multimillonario y, después, otra boda con el propio Miles - tienen un efecto benéfico en su víctima, pues suscitan en el abogado triunfador una paulatina conversión a los valores asociados al amor, diametralmente contrarios a los que han regido su vida laboral hasta la fecha. Un episodio destacado en este sentido es el discurso -de inequívocas resonancias al cine de Frank Capra (Cheshire \& Ashbrook, 2005, p. 129)- que Miles da ante la asociación de abogados matrimonialistas a la que pertenece, cuyo nombre, "N.O.M.A.N.", incide en la deshumanización de su profesión (noman). El discurso, pronunciado en el momento en el que cree gozar del amor de Marilyn [fig. 5], supone una suerte de iluminación para el personaje, que rompe la intervención que tenía prevista y en la que ya no cree, y en cambio habla desde el corazón, con lo que consigue conquistar con su mensaje a un auditorio cínico: Miles verbaliza aquí la oposición de valores que rige su transformación (el cinismo frente al amor), afirma el poder destructor del primero y los efectos benéficos del segundo4:

Amigos, el hombre que está ante vosotros es muy distinto del Miles Massey que os habló el año pasado sobre el tema "Los bienes conyugales tras un asesinato/suicidio”. (...) Porque hoy, por primera vez en mi vida, comparezco ante vosotros desnudo. Vulnerable. Y enamorado. Amor, palabra que los matrimonialistas evitamos. Es curioso: nos asusta un

\footnotetext{
4 Aunque sus palabras sean sinceras, Miles aún no las ha interiorizado: su transformación aún no es definitiva, pues, a la hora de validarlas, sigue priorizando el dinero sobre los sentimientos. Así se advierte cuando descubre que en realidad ha sido víctima de Marilyn, quien le ha arrebatado la mitad de su fortuna.
} 
sentimiento que de alguna manera es la semilla de lo que nos alimenta. Pues bien, hoy Miles Massey ha venido a deciros que el amor no debe darnos miedo, ni debe causarnos vergüenza. El amor es... bueno. El amor es bueno. Soy plenamente consciente de que estas observaciones serán recibidas con cinismo. El cinismo es el largo manto que revela nuestra indiferencia y oculta todo sentimiento humano. Pues dejadme que os diga que ese cinismo que creemos que nos protege en realidad sólo destruye: destruye el amor, destruye a nuestros clientes y en última instancia nos destruye a nosotros. Colegas, cuando nos llega un cliente confuso y enfurecido y dolido porque la llama de su amor se está debilitando y amenaza con morir, cacaso intentamos extinguir esa llama para luego poder tamizar los restos humeantes por una mísera recompensa? ¿O avivamos esa llama impagable, esa maravillosa manifestación de amor y la avivamos para que brille llena de vida? ¿Infundimos temor o confianza? ¿Intentamos destruir o construir? ¿Abordamos los problemas de nuestros clientes con cinismo o con amor? La decisión, por supuesto, depende de cada uno de nosotros. Yo por mi parte he dado el salto del amor y no hay vuelta atrás.

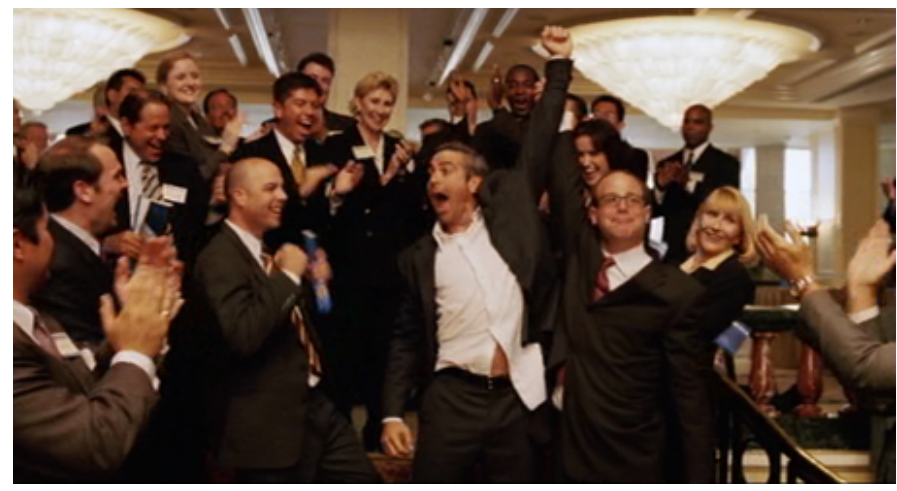

Aunque a renglón seguido el relato ilustra "la vuelta atrás" de Miles en tanto que se aviene a la iniciativa de su jefe de asesinar a Marilyn para recuperar su fortuna y la imagen del bufete, nuevos giros de guión posibilitarán que deje definitivamente atrás - y como él, Marilyn- su visión contractual y desconfiada de las relaciones, las cuales tienen su manifestación palmaria en un acuerdo pre-nupcial que Miles elaboró. Este acuerdo -que se estudia en la Universidad de Harvard-, firmado por las parejas antes de contraer matrimonio, constituye un "medio de dominación y control" (Conard, 2008, p. 117) de un cónyuge sobre el otro, en tanto que garantiza la imposibilidad de que el cónyuge que accede al matrimonio en una situación económica inferior se pueda lucrar a costa del miembro de la pareja con más dinero. A lo largo de todo el relato, durante las bodas reales y la simulada, la presencia y la ruptura de los "pre-nups" constituyen momentos decisivos en tanto que marcan el paso de los personajes de una situación de poder a otra de vulnerabilidad o viceversa. El gesto se repite en la conclusión, cuando Miles firma un contrato que garantiza que no persigue 
el dinero de Marilyn (y por tanto el control y el dominio sobre ella) y ella lo rompe, exponiéndose -o quedándose "con el culo al aire", según la expresión recurrente del film- a perderlo (y, por lo tanto, a confiar en la buena fe de Miles).

En definitiva, Miles y Marilyn terminan por adherirse a la máxima que en screwball comedies como La pícara puritana (L. McCarey, 1937) determina que el matrimonio se sustenta en la confianza mutua. Y con ello, dejan definitivamente atrás una concepción del mundo en la que el individuo busca el beneficio propio a costa de los demás.

\section{Ryan Binghan: el exterminador ingrávido}

Up in the Air constituye otra elocuente denuncia de los excesos del individualismo. Como Crueldad intolerable, esta comedia dramática muestra los demoledores efectos que el narcisismo tiene sobre el individuo que lo padece y sobre las personas allegadas a él, al tiempo que hace un énfasis mayor y más realista en los estragos que puede provocar en el ámbito laboral.

La película está protagonizada por Ryan Bingham (George Clooney), una suerte de exterminador social. Alguien que, como argumenta Sánchez-Escalonilla (2013), puede entenderse como la antítesis de George Bailey, el héroe doméstico por excelencia del cine norteamericano: Bingham destroza los hogares de los demás en lugar de ayudarles a preservarlos, reniega de la responsabilidad social, y no siente la menor compasión ante el sufrimiento ajeno.

Por el contrario, Bingham guarda notables puntos de encuentro con Miles Massey. Como éste, Bingham ha levantado una exitosa carrera profesional sobre el daño que ha causado a otras personas. Es el mejor especialista de una empresa que se dedica a despedir trabajadores de otras compañías, las cuales no tienen directivos con el valor y las capacidades precisas para afrontar ese tipo de situaciones. Bingham, que como Miles dispone el recurso de una implacable cualidad retórica, es el mejor profesional de los despidos, y su triunfo -son tiempos de crisis para el país y por tanto de bonanza para la empresa, recuerda su jefe- es el fracaso de los otros [fig. 6]. 


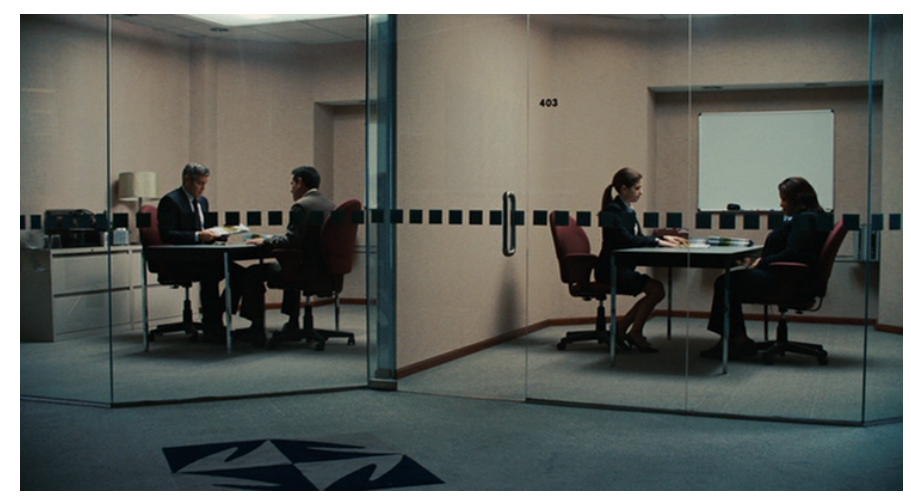

Como Miles, Bingham ha alcanzado esta "excelencia" profesional al haber interiorizado una filosofía de vida que lo hace inmune a los sentimientos y circunstancias de las personas con las que trata. La esencia de esta forma de ver la vida es, así, su desapego respecto a las demás personas, la determinación de "abortar cualquier interés profundo o duradero en los otros" para poder ser libre (Natoli, 2010). Esta distancia se apunta metafóricamente desde el título de la película - Up in the Air: "En el aire"- y encuentra un desarrollo argumentativo explícito en un motivo recurrente: el discurso motivacional que Bingham transmite por auditorios de Estados Unidos. En estas ocasiones Bingham enfatiza la necesidad de ser ingrávido, es decir, de eliminar las raíces que impiden el vuelo - por continuar con la metáfora- de las personas. En este discurso invita a despojarse del "peso de la mochila" que todos llevamos a nuestra espalda; y nada pesa más que las relaciones personales, consistentes a su entender en compromisos, secretos, negociaciones y otros fardos [fig. 7]. En la misma argumentación -y aquí estaría de acuerdo con Miles Massey-, Ryan Bingham invita a sus oyentes a aceptar su condición depredadora: las personas - dice- somos tiburones y no cisnes.

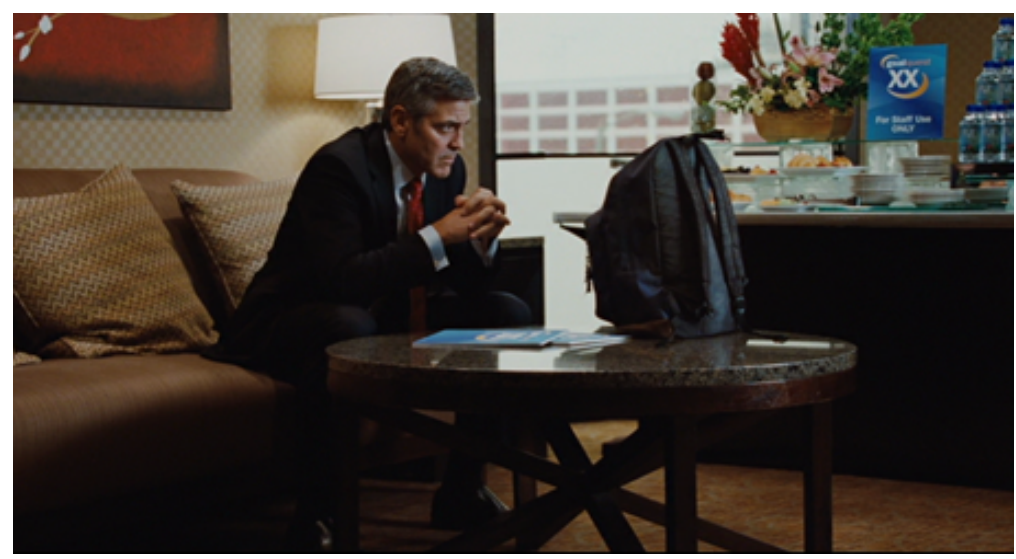


De la misma manera que Miles, Bingham parece vivir feliz en esta ilusión de autosuficiencia. Se define a sí mismo como alguien que se encuentra en casa cuando viaja, y de hecho lamenta tener que pasar "cuarenta y tres miserables días al año" en su apartamento. Su hogar, en cambio, está en los aviones, en los aeropuertos y en los hoteles, espacios emblemáticos del tránsito y el anonimato, de los “no-lugares" contemporáneos (Auge, 1993) en los que la identidad de las personas se diluye. Prueba de su adaptación a este entorno son sus conocimientos de Historia de los aeropuertos estadounidenses, y la singular secuencia en la que instruye a Natalie, una joven ayudante que le han asignado, sobre las pautas que debe seguir para moverse eficazmente en uno de ellos. Los objetivos vitales que Bingham se ha fijado se circunscriben igualmente a este hábitat: vive -o literalmente, trabaja- para rebasar una exclusiva cifra de millas de vuelo, gracias a lo cual obtendrá el título de "ejecutivo permanente" y alcanzará la inmortalidad en la forma de un avión que llevará su nombre5.

Según se advierte, Bingham comparte con Miles una ceguera cómica respecto a qué hace una vida lograda. Como las de aquel, sus relaciones personales resultan insignificantes. Hasta que la presencia de Alex - una ejecutiva que se mueve por el mundo como un alma afín a él- hace mella en su vida, Bingham hace gala de un fuerte desdén y escepticismo hacia las relaciones sentimentales y hacia el matrimonio. Ante Natalie reconoce no haber sentido nunca las febriles emociones del enamoramiento, y en otra ocasión le rebate los argumentos que ella da a favor del matrimonio: la conversación es algo de lo que ya goza, y la compañía en el momento de morir es una falacia, pues todo el mundo muere solo... salvo los miembros de las sectas que se juntan para matarse. En cuanto a las relaciones familiares - no había noticias de ellas en el caso de Miles-, el relato enfatiza en una de sus tramas el superficial trato que Bingham tiene con sus dos hermanas, las cuales se muestran mucho más unidas entre sí.

Si Crueldad intolerable reflejaba la superación del narcisismo a través de la irrupción del amor en la guerra de los sexos, $U p$ in the Air traza un parcial viaje

\footnotetext{
5 Como apunta Sánchez-Escalonilla (2013), se advierte aquí otra llamativa antítesis respecto a George Bailey, el protagonista de Qué bello es vivir (1946): si éste se compró en su juventud una maleta grande con la que soñaba poder viajar - sueño al que renunció incluso para el acostumbrado viaje de novios-, Bingham no hace otra cosa que reducir al máximo su equipaje y viajar sin denuedo. Si Bailey es un personaje vinculado a su familia y a su comunidad, Bingham se ha separado de las mismas.
} 
de redención para Bingham gracias al efecto benéfico que en él tienen los personajes femeninos con los que trata. Así, Natalie, sus dos hermanas y Alex fracturarán su narcisismo y le harán comprender la necesidad de abrirse a los otros, de enraizarse, de acercarse a la tierra. Natalie, su compañera de viajes laborales de la cual es mentor, además de cuestionarle sin ambages su "filosofía de mierda”, cumple la función dramática de espejo: siendo ambiciosa y capaz, renuncia al trabajo abrumada por la magnitud de los dramas que su actividad profesional detona, y sigue soñando con hacer compatible el trabajo con una relación amorosa y una vida familiar satisfactorias. Si Miles se aterraba ante las perspectivas de un futuro encarnado en la figura del fundador del bufete, Natalie se decide a romper con lo que promete ser un futuro pavoroso, encarnado en el presente en la figura (más amable, eso sí) de Bingham.

Up in the air reivindica también el valor significativo de las relaciones familiares a través de una trama que gira alrededor de la boda de la hermana menor de Bingham. Al asistir al acontecimiento, Bingham percibe la calidez de las relaciones de familia y amistosas de sus hermanas, y asume - con elegancia pero con presumible dolor - el papel residual que a él le corresponde en la celebración y, por extensión, advierte que él ocupa un lugar menor en sus vidas. Esta trama le da la oportunidad de recibir una iluminación sobre lo que es importante en la vida, cuando irónicamente se ve obligado a convencer al novio de su hermana de que debe dar el paso hacia el matrimonio: Bingham, un ejemplo de cómo evitar el compromiso, improvisa una argumentación en la que él mismo toma conciencia de que los mejores momentos de la vida tienen lugar en compañía: "Todos necesitamos un copiloto", afirma, fiel aún a su cosmovisión aérea de la vida.

El papel determinante en la toma de conciencia de su vacío vital corresponde a Alex, quien se presenta a sí misma como una versión femenina de Bingham, es decir, como alguien que no demanda relaciones comprometedoras. Su relación, concebida en principio por ambos como una satisfactoria pero insustancial aventura sexual, despierta en Bingham sentimientos que son frustrados por Alex a través de una fuerte revelación: ella cuenta con una familia en la esfera privada a la que no está, ni mucho menos, dispuesta a renunciar. Si Bingham ha descubierto en Alex por primera vez unos sentimientos de entrega genuinos, 
resulta que él no significa apenas nada - tan sólo "un paréntesis”- en la vida de ella [fig. 8].

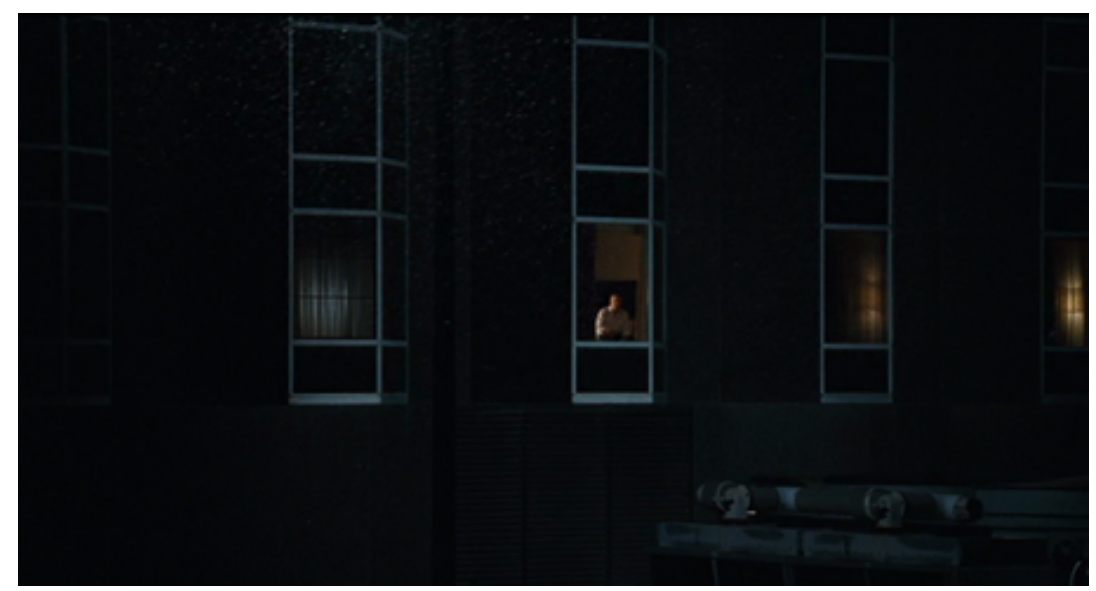

Esta dolorosa anagnórisis precede a la consecución a renglón seguido de su gran objetivo: Bingham alcanza la gran cifra de millas de vuelo que tanto ha perseguido. Pero, ahora que ha descubierto el valor de un sentimiento profundo y genuino de necesidad de otra persona, el logro se le antoja como algo verdaderamente insignificante. La tarjeta que lo acredita como "ejecutivo permanente" resulta ser sólo eso: una tarjeta. La constatación de este fracaso resuena en la reivindicación de la familia y de las relaciones de amor que son expresadas en las entrevistas realizadas en el desenlace del film a personajes/personas que han sido privados de su trabajo. Mirando a cámara, coinciden al afirmar que el valor del dinero y de las gratificaciones materiales palidece ante el valor que estas relaciones han tenido en sus vidas, especialmente en momentos dolorosos como los de un despido.

Up in the Air es un film que se recuerda por el sabor amargo que deja su desenlace. Esto es debido a que la genuina transformación de Bingham no se imbrica en un cambio de vida considerable: sin la compañía de Alex, él seguirá dando vueltas al mundo en soledad [fig. 9], además ahora siendo consciente de su vacío existencial. Sí es cierto que el espectador queda en parte aliviado al percibir el acercamiento de Bingham a su familia (cede a su hermana recién casada los privilegios que ha obtenido con sus millas de vuelo), y al ver cómo intercede de manera desinteresada a favor de Natalie, a la que ayuda a conseguir un nuevo empleo. Sin embargo, esta actitud de apertura hacia los otros, este darse cuenta de la necesidad de establecer relaciones personales verdadera queda -según decimos- cercenado por el hecho de no haber logrado su interés 
romántico, lo que le deja sumido en una profunda soledad. Así, como reconoce el propio Bingham, mientras todo el mundo tiene a alguien al final del día, a él sólo le quedará el consuelo de mirarlo todo desde las alturas.

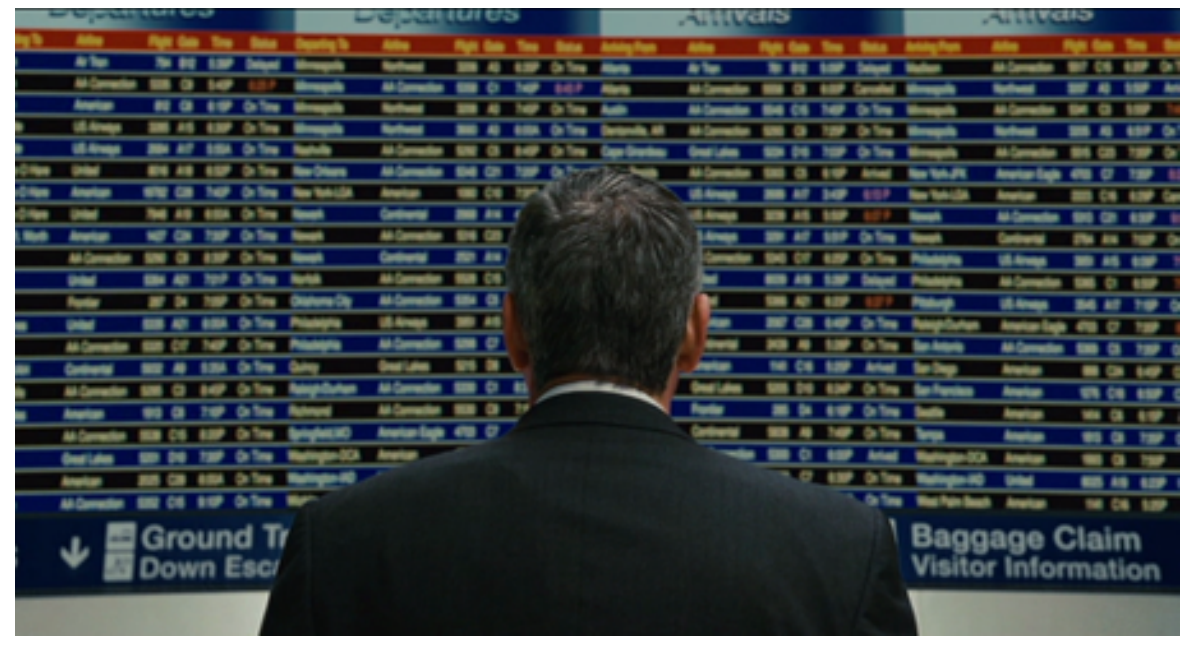

\section{Matt King: el rey que encuentra su patria}

La necesidad de superar el desarraigo constituye un tema recurrente en la breve filmografía de Alexander Payne (Echart, 2013, pp. 170-171). Desde A propósito de Schmidt (2002), sus protagonistas son sometidos a fuertes crisis de las que brota su anhelo de pertenencia y de alcanzar una vida significativa. Carol, la solitaria protagonista del cortometraje 14e Arrondisement, incluido en la película colectiva Paris, je t'aime (2006), encontrará su redención en un lugar la ciudad de París-, si bien lo habitual es que los protagonistas encuentren el sentido de sus vidas en relación con otros personajes que les hacen saberse valiosos y apreciados: Warren Schmidt encontrará consuelo a su vacío en la carta de un niño africano que apadrinó; Miles, el atribulado escritor de Entre copas (2004), en una mujer que sabrá mirarle por encima de sus fracasos.

Matt King (George Clooney), el protagonista de Los descendientes, es alguien que, al igual que Warren Schmidt, tendrá la oportunidad de superar su desarraigo a partir de un hecho luctuoso: el afrontamiento de los últimos días de vida de su mujer, Elizabeth. El relato, ambientado en Hawái, comienza con un prólogo en el que se registra mediante elipsis el accidente náutico que ella padece y que la postra en un coma irreversible. La vida irrumpe con todo su dolor también en los lugares más sublimes, como deja claro Matt en un monólogo interior: "El paraíso puede irse a la mierda". 
Este darse de bruces con la naturaleza quebradiza y limitada de la vida humana, en la que inevitablemente se cuelan los sinsabores y las amarguras, representa para Matt el punto de partida "de un proceso de revaluación de sus prioridades vitales y de redescubrimiento personal, gracias a lo cual se hará posible la recomposición familiar y la ansiada sintonía con sus hijas adolescentes [Alex y Scottie]" (Echart, 2013, p. 171). Payne somete a este rico abogado a un proceso de aprendizaje vital que vuelve a poner la clave en el desarrollo de unas sólidas relaciones personales - estrictamente familiares en este caso-, supeditadas hasta entonces a intereses propios, entre los cuales la dedicación profesional ocupaba una importancia fundamental. Este itinerario de aprendizaje le permitirá a Matt King estar a la altura de su apellido y de los roles -esposo, padre, heredero- que en la vida le corresponden (Martínez, 2012, p. 23).

Aunque Matt comparta con Miles y Bingham la carencia de unas relaciones personales auténticas y llegue a una misma conclusión que ellos -el reconocimiento sincero del valor de las mismas-, su composición psicológica ofrece matices bien diferenciados, más moderados y menos vitriólicos, que dejan entrever la mirada compasiva de Alexander Payne. Aunque haya desatendido las necesidades afectivas de sus seres más próximos, Matt no vive para alimentar su ego. Más que narcisista, él es alguien que en el discurrir de los años ha perdido la sensibilidad emocional, alguien que no ha rehuido deliberadamente de los compromisos personales sino que no ha caído en la cuenta de las responsabilidades que le eran propias. Tampoco es un cínico, ni un personaje inmoral, ni se regodea en su buen hacer profesional, ni aspira a amasar una fortuna mayor. $\mathrm{Y}$ aunque con su riqueza ha pretendido sustituir ciertas responsabilidades familiares (Guyette, 2013, p. 356), en su relación con el dinero básicamente destaca su templanza, y prueba de ello es la prudencia con la que ha gestionado la herencia recibida, en contraste con el proceder de otros beneficiados.

También a diferencia de Miles y Bingham, Matt es consciente desde un primer momento de cuáles son los aspectos en que debe enmendarse. En el monólogo interior antes citado, Matt reconoce ante su mujer postrada en la cama del hospital que ésta ha conseguido llamar su atención, y que él está dispuesto a cambiar para ser un buen padre y marido. Conforme presumiblemente a una 
división de roles tradicional, según la cual el hombre se vinculaba a la esfera del trabajo para dejar a la mujer la gestión de la familia y los asuntos del corazón (Bellah \& Madsen \& Sullivan \& Swidle \& Tipton, 1989, pp. 120-126), Matt reconoce que en el ámbito familiar siempre ha sido el "suplente", y ahora no tendrá más remedio que ocupar sin reservas el primer plano del cuidado y educación de sus hijas. El grueso de la historia consiste en ver cómo Matt reorienta su relación con ellas, ante quienes se siente de entrada perplejo: Scottie, la menor, aunque nunca muestra una queja hacia su padre, sí da problemas en el colegio con su espontaneidad y su franqueza; Alex, la mayor, ha entrado en una espiral de "chicos y drogas", y su actitud hacia Matt es en principio hostil y acusatoria.

El relato muestra con sutileza cómo se reconduce hacia la armonía la relación entre el padre y las dos hijas. Este entendimiento surge fundamentalmente aunque no solo- de compartir los tres (junto con Sid, un amigo de Alex) dos grandes situaciones: encontrar al amante de Elizabeth para darle la noticia de su accidente y los rituales de despedida propios del fallecimiento de su mujer y madre, respectivamente. La primera situación permite que Matt teja una complicidad con Alex, su hija mayor. Principalmente porque los dos forman un tándem bien avenido desde que Alex se implica en la misión de ayudar a su padre a localizar e informar al amante (lo que incluye una divertida charada que satisface tanto al padre como a la hija), y también porque los dos comparten una información que privan a Scottie: que la muerte de su madre es inevitable, y que ésta tenía un amante. Por su parte, ajena por tanto de las verdaderas intenciones de su padre y hermana, Scottie disfruta de esta misión que para ella adopta la forma de unas vacaciones en familia: disfruta de los juegos en la playa y de simulacros de la domesticidad, como puede ser el hecho de juntarse todos a ver la televisión en la habitación del hotel. El viaje a la isla de Kaui al encuentro del amante de Elizabeth permite además reforzar el vínculo familiar, al compartir Matt con sus hijas anécdotas referidas al pasado de su madre; y también al proyectarse los tres hacia el futuro, cuando Scottie plantea la posibilidad de pasar unos días de acampada en las tierras que Matt está pensando vender. 
Al regreso de este viaje, Matt, Alex y Scottie se encaran con la difícil tarea de enfrentarse a la muerte de Elizabeth. La complicidad de Matt con su hija mayor se refuerza en la preocupación común de transmitir la noticia a Scottie, y con la defensa que Alex hace de su padre ante las acusaciones que su abuelo vierte sobre éste. El abrazo de Matt con Scottie cuando ésta es informada del destino de su madre, y el abrazo de Matt con Alex posterior a la despedida de ésta con su madre, sellan físicamente la reconciliación familiar, y los prepara para realizar en comunión el ritual funerario de esparcir las cenizas de Elizabeth sobre las aguas marinas de Hawái. El relato concluye con una escena de sencilla felicidad doméstica, en la que los tres se juntan en el salón de su casa para ver un documental de pingüinos mientras comparten helado.

Si Matt cumple así su promesa de enmendarse para ser un buen padre, poco margen tiene - aunque lo logra-para volver a ser un buen marido. Si Alex le echa en cara a Matt que no ha cuidado de ella, lo propio y con mayor virulencia hace su suegro (Scott) en relación a Elizabeth. Aunque intervenga solamente en dos secuencias, su suegro arremete sin piedad contra Matt, al que juzga responsable de la suerte que ha corrido su hija: cuando éste le da la mala noticia del accidente y de su inminente desenlace, Scott ensalza la vitalidad y fortaleza de Elizabeth, que contrasta a su entender con la inútil tarea de Matt de amasar dinero, por la cual no ha atendido a las necesidades de su mujer; en la segunda secuencia, cuando Scott acude con su mujer al hospital para despedirse de su hija, incide en las mismas ideas: Matt no ha estado a la altura como marido y, mientras Liz se va a morir, él va a engordar su fortuna con la venta de unas tierras. En definitiva, al juzgar a Matt, este personaje secundario establece una nítida dicotomía entre, por un lado, el amor y la atención debida al cónyuge ${ }^{6}$ y, por otro lado, una dedicación profesional absorbente que se realiza con miras a incrementar la riqueza.

Aunque las palabras de Scott resultan hirientes para Matt y sean maniqueas en su adjudicación de las responsabilidades, dejan entrever una verdad: Matt, efectivamente, no supo cubrir las necesidades de su mujer, de lo que es prueba el hecho de que ella buscara su felicidad a través de la infidelidad. Al conocer este hecho, Matt reacciona con estupor, y a renglón seguido descarga toda su ira

${ }^{6}$ Una atención que él mismo ilustra al cuidar con primor de su mujer, la cual padece un alzheimer severo. 
y sus reproches sobre la figura inerte de su mujer. Pero el conjunto de experiencias que atraviesa en el viaje a la isla de Kaui -la revisitación del pasado y de un tiempo feliz junto a Elizabeth, el acercamiento a sus hijas, el reconocimiento de la necesidad de preservar el territorio que heredó y, en definitiva, su enraizamiento real con sus seres queridos y con el entorno del que provienen- le permitirán afrontar el tramo final de su matrimonio con nuevos ojos. Matt se despide de ella con una honesta declaración de amor. En estas dos escenas simétricas, Matt pasa de ver su relación matrimonial desde un punto de vista egocéntrico, en el que se ve como una víctima con derecho a reprochar las afrentas recibidas, a reconocer a Elizabeth como un regalo valioso que ha recibido.

Como se ha ido apuntando, el desarrollo de estas reconciliaciones familiares tiene como telón de fondo una trama en la que está en juego la posible venta de unas tierras que Matt y sus primos hawaianos han heredado. En primera instancia, Matt parece proclive a vender ese terreno, si bien no muestra la ansiedad o determinación de sus familiares al respecto, con lo que se advierte que la avaricia no es uno de sus vicios. Sin embargo, el primer diálogo que se formula sobre esta operación financiera viene a cargo de un personaje menor que deja entrever la oposición entre el enorme montante económico y los daños medioambientales que se derivarán de la transacción. De esta manera, se advierte que se trata de optar entre un bien particular y un bien comunitario, entre el "yo" (Matt y sus familiares) y el "nosotros" (el conjunto de los habitantes de la isla).

El valor de la tierra como espacio de vínculo entre las personas se refuerza en la secuencia en la que Matt y sus hijas contemplan in situ el terreno en venta [fig. 10]. Como ya se ha mencionado, aquí acontece el recuerdo de unos días felices en el pasado de Matt y, gracias a la intervención de Scottie, la posibilidad de que se repitan en el futuro. Que el amante de Elizabeth vaya a ser uno de los beneficiarios de la operación económica no ayuda desde luego a que Matt se pronuncie a su favor, pero lo decisivo para que la rechace estriba en su asimilación -la película hace énfasis en las imágenes de los antepasados familiares- de los lazos que unen a las personas, y en primer lugar a la familia, a la que antes había considerado, de manera pesimista, como un archipiélago 
de islas que poco a poco se separan [fig. 11]. El descubrimiento del vínculo real a su familia se amplifica con esta trama de filiación a la Madre Tierra, a un espacio al que también se pertenece. De esta manera Matt, al igual que Bingham, experimenta su particular viaje ${ }^{7}$ del desarraigo al enraizamiento vital.
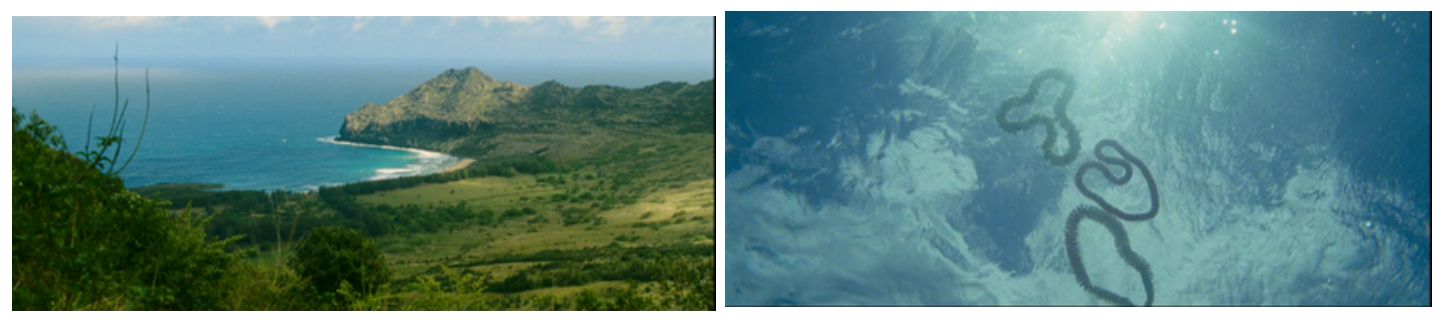

\section{Conclusión}

Además de las ficciones optimistas referidas a las posibilidades del individuo el self-made man, el hombre hecho a sí mismo- para ascender en la escala social, el Sueño Americano ha suscitado muchas otras que advierten de los peligros y perversiones que pueden derivarse en ese afán de superación, que tantas veces se cobra un precio excesivo. En esta segunda línea se sitúa este artículo, en el que se han analizado tres relatos cinematográficos protagonizados por George Clooney. La experiencia del éxito de los protagonistas masculinos de Crueldad intolerable, Up in the Air y Los descendientes deviene insatisfacción o fracaso vital, aspecto en el que coinciden con un considerable número de "bildungsromans de la mediana edad" (Levinson, 2012, p. 128) de las últimas décadas, algunos de los cuales son A propósito de Schmidt (A. Payne, 2002), Lost in Translation (S. Coppola, 2003) o Flores rotas (J. Jarmusch, 2005).

Crueldad intolerable y Up in the Air presentan unos protagonistas masculinos dominados por un narcisismo al que se han entregado para poder triunfar en la esfera profesional. Sin embargo, en ambos casos los placeres de una vida sin ataduras y entregada al cultivo del yo se revelan en un momento banales, y los relatos se estructuran en torno a los viajes de redención de estos personajes envilecidos por su trabajo, los cuales aciertan a encontrar el sentido y el logro de sus vidas en las relaciones afectivas, sean de amor o familiares. Si Up in the Air

\footnotetext{
7 Como es habitual en la filmografía de Payne (Echart, 2013, p. 179), el viaje de identidad viene acompañado de un énfasis en los desplazamientos físicos de los personajes, característica que se cumple también en Los descendientes: Matt y sus hijas están en continuo tránsito hasta que, al fin unidos, descansan juntos en la escena que cierra la película, ya comentada.
} 
juega con la metáfora de la ingravidez para referirse al hombre sin compromisos personales, Los descendientes enfatiza el elemento de la tierra para subrayar la pertenencia del individuo a una comunidad, de la cual la familia constituye su primera instancia. Las tres películas, en definitiva, son historias de redención de profesionales triunfadores que, en su camino hacia el éxito, fueron dejando con deliberación o no- víctimas a su paso: terceros anónimos -las víctimas de sus clientes- en el caso de Crueldad intolerable y Up in the Air, y un matrimonio y una familia desatendida en el caso de Los descendientes. Conscientes al fin de los efectos nocivos de su individualismo radical, desechas a la postre sus aspiraciones de encontrar la satisfacción vital en su trabajo, Miles, Ryan y Matt descubrirán que el verdadero éxito de sus vidas se encuentra en su obligada apertura a sus seres más cercanos.

\section{Referencias bibliográficas}

Auge, M. (1993). Los «no lugares». Espacios del anonimato. Barcelona: Gedisa.

Bellah, R. N., Madsen, R., Sullivan, W. M., Swidler, A., Tipton, S. M. (1989). Hábitos del corazón. Madrid: Alianza Editorial.

Cheshire, E., Ashbrook, J. (2005). Joel and Ethan Coen. Harpenden: Pocket Essentials.

Conard, M. T., (2008). The Philosophy of The Coen Brothers. Lexington: University Press of Kentucky.

Doom, R. P. (2009). The Coen Brothers. Unique Characters of Violence. Santa Barbara: Greenwood Publishing Group.

Dyer, R. (2001). Las estrellas cinematográficas. Barcelona: Paidós.

Echart, P. (2013). En busca de armonía: un acercamiento a los personajes de Alexander Payne a través del cortometraje 14e Arrondissement. En R. Gutiérrez (Coord.), Poéticas de la persona. Creación, responsabilidad y vigencia en la comunicación pública y la cultura. Estudios en homenaje a Juan José García-Noblejas (pp. 170-180). Salamanca: Comunicación Social.

Echart, P. (2005). La comedia romántica del Hollywood de los años 30 y 40. Madrid: Cátedra.

Egri, L. (1960). The Art of Dramatic Writing. Nueva York: Simon \& Schuster.

Guyette, F. (2013). The Descendants and Pastoral Care. Pastoral Psychology, 62 (3), 355-360. http://download.springer.com/static/pdf/616/art\%253A10.1007\%252Fs 11089-012-0447y.pdf?auth66=1389954355__19477e07ec86c714d6724390931ff4d3\&ext=. pdf DOI 10.1007/s11089-012-0447-y 
Levinson, J. (2012). The American Success Myth on Film. Nueva York: Palgrave MacMillan.

Martínez, B. (2012). La herencia que nos queda. Dirigido por, (418), 23-24.

McDonald, P. (2013). Hollywood Stardom. Malden (MA), Oxford: WileyBlackwell.

Natoli, J. (2010). The Perils of Being Up in the Air. Senses of Cinema, (54). http://sensesofcinema.com/2010/feature-articles/the-perils-of-beingup-in-the-air/

Orellana, J. (2010). Celuloide posmoderno: narcisismo y autenticidad en el cine actual. Madrid: Encuentro.

Rowell, E. (2007). The Brothers Grim. The Films of Ethan and Joel Coen. Lanham: The Scarecrow Press.

Sánchez-Escalonilla, A. (2013). "From Hoover to Bush Jr. - home and crisis scripts in U.S. social cinema"./Jump Cut. A Review of Contemporary Media/, http://www.ejumpcut.org/currentissue/SanchezCrisisTales/text.html 55.

Sickels, R. C. (2008). "We're in a tight spot!": The Coen Brothers' Screwy Romantic Comedies. Journal of Popular Film and Television, 36 (3), 114122. http://www.tandfonline.com/doi/pdf/10.3200/JPFT.36.3.114122\#.UtXE3tLuLEo DOI: 10.3200/JPFT.36.3.114-122

Sterritt, D. (2012). George Clooney. The Issues Guy. En M. Pomerance (ed.), Shining in Shadows: Movie Stars of the 20oos (pp. 220-237). New Brunswick, New Jersey, Londres: Rutgers University Press.

Traub, J. (2008). The Celebrity Solution. The New York Times (Magazine). http://www.nytimes.com/2008/03/09/magazine/o9CELEBRITYt.html?pagewanted $=$ all\&_r $=0$ 